\title{
Genetic alterations of triple negative breast cancer (TNBC) in women from Northeastern Mexico
}

\author{
GRECIA I. USCANGA-PERALES ${ }^{1,2^{*}}$, SANDRA K. SANTUARIO-FACIO ${ }^{3 *}$, \\ CELIA N. SANCHEZ-DOMINGUEZ ${ }^{2}$, SERVANDO CARDONA-HUERTA ${ }^{4}$, \\ GERARDO E. MUÑOZ-MALDONADO ${ }^{5}$, PABLO RUIZ-FLORES ${ }^{6}$, JOSE R. BARCENAS-WALLS ${ }^{1}$, \\ LUIS E. OSUNA-ROSALES ${ }^{1}$, AUGUSTO ROJAS-MARTINEZ ${ }^{3}$, JUAN FRANCISCO GONZALEZ-GUERRERO ${ }^{7}$, \\ JAVIER VALERO-GOMEZ ${ }^{4}$, GABRIELA S. GOMEZ-MACIAS ${ }^{8}$, ALVARO BARBOSA-QUINTANA $^{8}$, \\ ORALIA BARBOZA-QUINTANA ${ }^{9}$, RAQUEL GARZA-GUAJARDO ${ }^{9}$ and ROCIO ORTIZ-LOPEZ ${ }^{3}$ \\ ${ }^{1}$ Centro de Investigación y Desarrollo en Ciencias de la Salud; ${ }^{2}$ Departamento de Bioquimica y Medicina Molecular, Facultad \\ de Medicina, Universidad Autonoma de Nuevo Leon, Monterrey, Nuevo Leon 66460; \\ ${ }^{3}$ Escuela de Medicina y Ciencias de la Salud; ${ }^{4}$ Centro de Cancer de Mama, Hospital San Jose, Tecnologico de Monterrey, \\ Monterrey, Nuevo Leon 64710; ${ }^{5}$ Servicio de Cirugia General, Hospital Universitario Dr. Jose Eleuterio Gonzalez, \\ Universidad Autonoma de Nuevo Leon, Monterrey, Nuevo Leon 66460; ${ }^{6}$ Departamento de Medicina Molecular, \\ Facultad de Medicina, Universidad Autonoma de Coahuila, Torreon, Coahuila 27000; ${ }^{7}$ Servicio de Oncologia, \\ Centro Universitario Contra el Cancer, Hospital Universitario Dr. Jose Eleuterio Gonzalez, \\ Universidad Autonoma de Nuevo Leon, Monterrey, Nuevo Leon 66460; \\ ${ }^{8}$ Servicio de Patología, Hospital San Jose, Tecnologico de Monterrey, Hospital San Jose, Monterrey, Nuevo Leon 64710; \\ ${ }^{9}$ Servicio de Anatomia Patologica y Citopatologia, Hospital Universitario Dr. Jose Eleuterio Gonzalez, \\ Universidad Autonoma de Nuevo Leon, Monterrey, Nuevo Leon 66450, Mexico
}

Received May 31, 2018; Accepted November 30, 2018

DOI: $10.3892 /$ ol.2019.9984

\begin{abstract}
Triple negative breast cancer (TNBC) is a subtype of breast cancer of heterogeneous nature that is negative for estrogen receptor (ER), progesterone receptor (PR) and growth factor human epidermal 2 (HER2) following immunohistochemical analysis. TNBC is frequently characterized by relapse and reduced survival. To date, there is no targeted therapy for this type of cancer. Chemotherapy, radiotherapy, and surgery remain as the standard treatments options. The lack of a target therapy and the heterogeneity of TNBC highlight the need to seek new therapeutic options. In this study, fresh tissue samples of TNBC were analyzed with a panel of 48 driver genes (212 amplicons) that are likely to be therapeutic targets. We found intron variants, missense, stop gained and splicing variants in TP53, PIK3CA and FLT3
\end{abstract}

Correspondence to: Dr Rocio Ortiz-Lopez, Escuela de Medicina y Ciencias de la Salud, Tecnologico de Monterrey, 3000 Ave. Morones Prieto, Monterrey, Nuevo Leon 64710, Mexico

E-mail: rortizl@itesm.mx

*Contributed equally

Key words: triple negative breast cancer, TP53, PIK3CA, FLT3, new generation sequencing, target therapy genes genes. Interestingly, all the analyzed samples had at least two variants in the TP53 gene, one being a drug response variant, rs1042522, found in $94 \%$ of our samples. We also found seven additional variants not previously reported in the TP53 gene, to the best of our knowledge, with probable deleterious characteristics of the tumor suppressor gene. We found four genetic variants in the PIK3CA gene, including two missense variants. The rs2491231 variant in the FLT3 gene was identified in 84\% $(16 / 19)$ of the samples, which not yet reported for TNBC, to the best of our knowledge. In conclusion, genetic variants in TP53 were found in all TNBC tumors, with rs1042522 being the most frequent (94\% of TNBC biopsies), which had not been previously reported in TNBC. Also, we found two missense variants in the $P I K 3 C A$ gene. These results justify the validation of these genetic variants in a large cohort, as well as the extensive study of their impact on the prognosis and therapy management of TBNC.

\section{Introduction}

Breast cancer (BC) is the most common neoplasm among women worldwide, according to Global cancer statistics (GLOBOCAN) there will be about 2.1 million newly diagnosed female breast cancer cases in 2018, accounting for almost 1 in 4 cancer cases among women (1). In Mexico, BC is the most common cancer in women since 2006 (2). This neoplasm comprises a group of biologically different entities with different pathological and molecular features involved in 
their staging and therapeutic management. Based on standard immunohistochemistry tests (IHT), BC is classified into three main groups: 1) luminal: Positive for hormonal receptors; 2) HER2 overexpressed, and 3) Triple-negative BC (TNBC). TNBC is characterized by the absence of hormone receptor expression and lack of HER2 amplification (3-5). Targeted therapies are available for luminal and HER2 amplified categories, but there is no treatment option for TNBC. Therefore, the precise classification in clinically relevant subtypes is of particular importance for therapeutic decision-making. TNBC represents $15-20 \%$ of the BC and is more frequent in young women and individuals of African and Hispanic heritage (6). Due to the lack of expression of therapeutic targets, chemotherapy remains a primary treatment option, along with radiotherapy and surgery $(7,8)$. While TNBC patients respond better to chemotherapy than patients with non-TN BC (nTNBC), TNBC patients who do not respond eventually develop the metastatic form of the disease. This form is virtually incurable, so TNBC is characterized by its aggressive clinical course and poor prognosis compared to other BC subtypes (9).

The absence of therapeutic biomarkers of TNBC requires determining the molecular profile of TNBC tumors to propose therapeutic targets. The efforts of the complete genome sequencing have shown that TNBC presents alterations of TP53 in up to $80 \%$ of the cases, followed by a broad set of genes with lower frequencies, such as $P I K 3 C A$ and $R B(10,11)$.

Next generation sequencing (NGS) is a powerful method that allows visualizing the genomic landscape of tumors and revealing tumor heterogeneity through the detection of genetic variants that occur in a low percentage (12). NGS has been used to sequence genes linked to cancer $(11,13,14)$ to discover mutations that can modulate the repair capacity as well as the response to chemotherapy (15). Besides, the increased heterogeneity correlates with poor patient outcomes to treatment $(16,17)$.

In the present study, we characterize the genetic alterations of TNBC in fresh tissue biopsies from TNBC patients from the Northeast of Mexico through NGS, with the aim of identifying alternative driver mutations, including those predictive of sensitivity and/or clinical response to chemotherapy and new molecularly directed drugs.

\section{Materials and methods}

Patients and tissue sample. The protocol was approved by the Ethics and Research Committee of the School of Medicine (Universidad Autonoma de Nuevo Leon), with the registered number BI11-005. Each participant was asked to sign an informed consent. Demographic information and personal data were obtained from the medical records. Tissue samples were obtained from patients under clinical and radiological suspicion of locally advanced $\mathrm{BC}$ (Tumor size $>$ $2 \mathrm{~cm}$, palpable ipsilateral lymph nodes, and ulceration) (18) of University Hospital "Dr. José Eleuterio Gonzalez" between 2011 and 2014. Core biopsies were obtained using a $12 \mathrm{Fr}$ gauge $\left(\right.$ Bard $\left.^{\circledR}\right)$. Each patient underwent histopathological diagnosis by immunohistochemistry (ER, PR, HER2 and Ki67 status).
DNA isolation. Genomic DNA was obtained from biopsies with the DNeasy Blood and Tissue kit (Qiagen, Inc., Valencia, CA, USA) following the manufacturer's instructions (www.qiagen. com). The tissues were lysed by incubation with proteinase $\mathrm{K}$ at $56^{\circ} \mathrm{C}$ until the tissues were completely lysed, followed by purification and elution on a centrifugation column. The DNA was initially quantified in the Nanodrop 8000 spectrophotometer (ratio 260/280> 1.8; Thermo Fisher Scientific, Inc., Waltham, MA, USA). A subsequent quantification was done using Quant-iT Picogreen (Thermo Fisher Scientific, Inc.) following the instructions from the manufacturer. DNA concentration was then adjusted to $50 \mu \mathrm{g} / \mathrm{ml}$.

Sequencing. Libraries were constructed using the TruSeq Amplicon Cancer Panel (FC-130-1008) (19) a kit available on https://www.illumina.com/ that has been designed to cover mutational hotspot of 48 genes associated with cancer that can generate data for treatment with drugs approved by the US Food and Drug Administration. $250 \mathrm{ng}$ of DNA was mixed with the pool of oligonucleotides containing all the primers to generate 212 amplicons ( 35 kilobases) from hotspot regions of 48 genes. Libraries were amplified in the Eppendorf EP Master Faster City thermal cycler (Eppendorf, Hamburg, Germany). The quality of the libraries were evaluated in Agilent 2100 Bioanalyzer (Agilent Technologies, Inc., Santa Clara, CA, USA). Each library was standardized according to the manufacturer's instructions. Finally, libraries were adjusted at a concentration of $12 \mathrm{pM}$. Library pools were loaded into a MiSeq Reagent Kit v3 cartridge (Illumina, Inc., San Diego, CA, USA), and each library pool was sequenced on an Illumina MiSeq instrument using a 150 paired-end design.

Data analysis. The Human Genome build 19 construct (hg19) was used as the reference genome. Alignment and the variant calling were performed with the MiSeq Reporter TruSeq Amplicon (Illumina, Inc.). Variants were identified using Variant Interpreter (Illumina Inc.). Reading quality Q >90 and reading depth $>60$ were used. Variants with an allelic frequency less than $5 \%$ were discarded. The clinical significance of the variants was determined using the ClinVar tool. Also, the tool Polymorphism Phenotyping v2 (Polyphen-2) was applied to predict the possible impact of an amino acid substitution on the function of the proteins.

\section{Results}

Patients. A total of 29 frozen tissue biopsies classified as TNBC were collected. However, there were 19 tissue samples available for sequencing. The average age of these 19 women was 51 years, with a BMI average of 27.5. All participants were free of metastases at the time of participating in the study. The main clinical information of the patients is shown in Table I.

TNBC sequencing. We found 65 variants in 25 of the 48 genes analyzed. Of these genes, TP53, PIK3CA and FLT3 genes presented nonsense, missense, stop-gained variants, or variants in the splicing region with pathogenic significance. In the rest of the genes, intronic and variants that have been classified 
Table I. Clinical characteristics of women participating in this study. The average age at diagnosis was 52 years, with an age range of 41-71 years. The average Body Mass Index was 27.31. No patient presented metastasis at the time of the study. The participating women were in clinical stages II and III.

\begin{tabular}{|c|c|c|c|}
\hline Clinical characteristics & $\mathrm{n}=19$ & Range & $\begin{array}{l}\text { Standard } \\
\text { deviation }\end{array}$ \\
\hline Age at diagnosis, years & 52 & $41-71$ & 8.63 \\
\hline $\mathrm{BMI}, \mathrm{Kg} / \mathrm{m}^{2}$ & 27.31 & $20.78-37.01$ & 4.27 \\
\hline \multicolumn{4}{|l|}{ Menopause status } \\
\hline Pre & 10 & $53 \%$ & \\
\hline Post & 9 & $47 \%$ & \\
\hline \multicolumn{4}{|l|}{ Diabetes mellitus $^{\mathrm{a}}$} \\
\hline Yes & 3 & $16 \%$ & \\
\hline No & 16 & $84 \%$ & \\
\hline Glucose levels, mg/dl & 101.8 & $91-116$ & 7.69 \\
\hline \multicolumn{4}{|l|}{ Number of children ${ }^{\mathrm{b}}$} \\
\hline Nulliparous & 0 & $0 \%$ & \\
\hline 1 to 2 & 6 & $32 \%$ & \\
\hline$>3$ & 13 & $68 \%$ & \\
\hline \multicolumn{4}{|l|}{ Smoking } \\
\hline Yes & 1 & $5 \%$ & \\
\hline No & 18 & $95 \%$ & \\
\hline \multicolumn{4}{|l|}{ TNM } \\
\hline $\mathrm{T} 1$ & 0 & $0 \%$ & \\
\hline $\mathrm{T} 2$ & 9 & $47 \%$ & \\
\hline $\mathrm{T} 3$ & 7 & $37 \%$ & \\
\hline $\mathrm{T} 4$ & 3 & $16 \%$ & \\
\hline N0 & 0 & $0 \%$ & \\
\hline N1 & 13 & $68 \%$ & \\
\hline N2 & 4 & $21 \%$ & \\
\hline N3 & 2 & $11 \%$ & \\
\hline M0 & 0 & $0 \%$ & \\
\hline \multicolumn{4}{|l|}{ Clinical stage } \\
\hline I & 0 & $0 \%$ & \\
\hline II & 11 & $58 \%$ & \\
\hline III & 8 & $42 \%$ & \\
\hline
\end{tabular}

${ }^{\mathrm{a}}$ Confirmed at $\mathrm{BC}$ diagnosis, ${ }^{\mathrm{b}}$ Number of pregnancies. $\mathrm{T}$, size of primary tumor; $\mathrm{N}$, node status; TNM, tumor-node-metastasis; BMI, Body Mass Index.

as benign were observed. Fig. 1A shows the distribution of each gene variants. All the samples presented between 18 and 26 genetic variants. Fig. 1B shows the distribution of the variants of each gene analyzed, including the non-reported variants found in $A T M, G N A 11, G N A Q, N R A S, P I K 3 C A$, PTEN, RB1, SMAD4, SRC and TP53. The highest number of variants were found in the intronic regions (from 10 to 14 per sample) and $49 \%$ were in exonic regions (32/65). An average of 5 synonymous variants were identified regarding the type of variant, and 2 to 5 missense variants were found per sample (Fig. 2). TP53 was mutated in all the samples and presented
15 variants, of which $7(46 \%)$ were missense variants. We found four genetic variants in the PIK3CA gene, including two missense variants. FLT3 presented one variant in the splicing region between exons 14 and 15 (Table II).

TP53 variants. When comparing the variants found in each sample, we observed the exonic variant rs1042522 located in the TP53 gene in $94 \%$ of the TNBC biopsies (18/19). In addition, we found rs1625895, rs34949160, rs1800372, rs5877580, rs121912654, rs28934574 and rs11540652 variants of TP53. The first three variants, located in intron 6 of the gene, are classified as benign according to the ClinVar database. The rs5877580, rs121912654, and rs11540652 variants are probably damaging variants based on PolyPhen-2 with score s of $0.993,0.998$ and 0.992 respectively. The rs28934574 is a variant with a possibly damaging score $(0.583)$. We found 7 non-reported exonic variants. Five of these variants are SNVs: p.Arg213Ter, p.His179Gln, p.Arg196Ter and p.Ser269Arg. Three variants correspond to insertion or deletion of a nucleotide: p.Asn268ThrfsTer77, p.Gys135AlafsTer35 and p.Cys275PhefsTer71. All these variants affect part of the DNA binding domain of $\mathrm{p} 53$.

FLT3. The rs2491231 variant of the FLT3 gene, which has not been reported before for TNBC, was found in 84\% (16/19) of the samples. This variant is located in the splicing region between exons 14 and 15 .

PIK3CA. Two missense variants were observed in PIK3CA: The exonic variant rs121913279 of the PIK3CA gene was detected in one sample. This variant has been classified as Pathogenic/Likely pathogenic in ClinVar and the exonic variant, p.Glu1012GIn, that has not yet been reported.

\section{Discussion}

NGS is a very useful tool in disease characterization of multigenic origin such as cancer, where the accumulation of a series of mutations in several genes is the key to tumor development. The ability of NGS to evaluate the mutational status of a relevant set of oncogenes and tumor suppressor genes in a single test, such as those evaluated in this work could be helpful to identify TNBC mutation drivers to design better diagnostic and therapeutic strategies. TruSeq Amplicon Cancer Panel was validated in 2015 (19), with the purpose of detecting somatic mutations through hundreds of mutational hotspots of essential genes related to cancer, including PIK3CA, TP53, and EGFR. Mutations in these genes are related to cancer and are involved in many cellular pathways.

Previously, a difference in the pattern of somatic mutations among the intrinsic subtypes of $\mathrm{BC}$ has been observed (11). We found variants in 25 genes, of which variants in TP53, PIK3CA and FLT3 showed missense and non-sense variants, or variants in the splicing region. Tumors with a triple negative phenotype have a high prevalence of mutations in TP53 (80\%) vs. luminal breast cancer (12\%). In this work, we analyze the triple negative phenotype, observing that the gene with a high prevalence of exonic variants was TP53, as previously indicated (20,21). Although in 2012 it was reported that most of the TP53 variants in basal tumors were non-sense and 
A
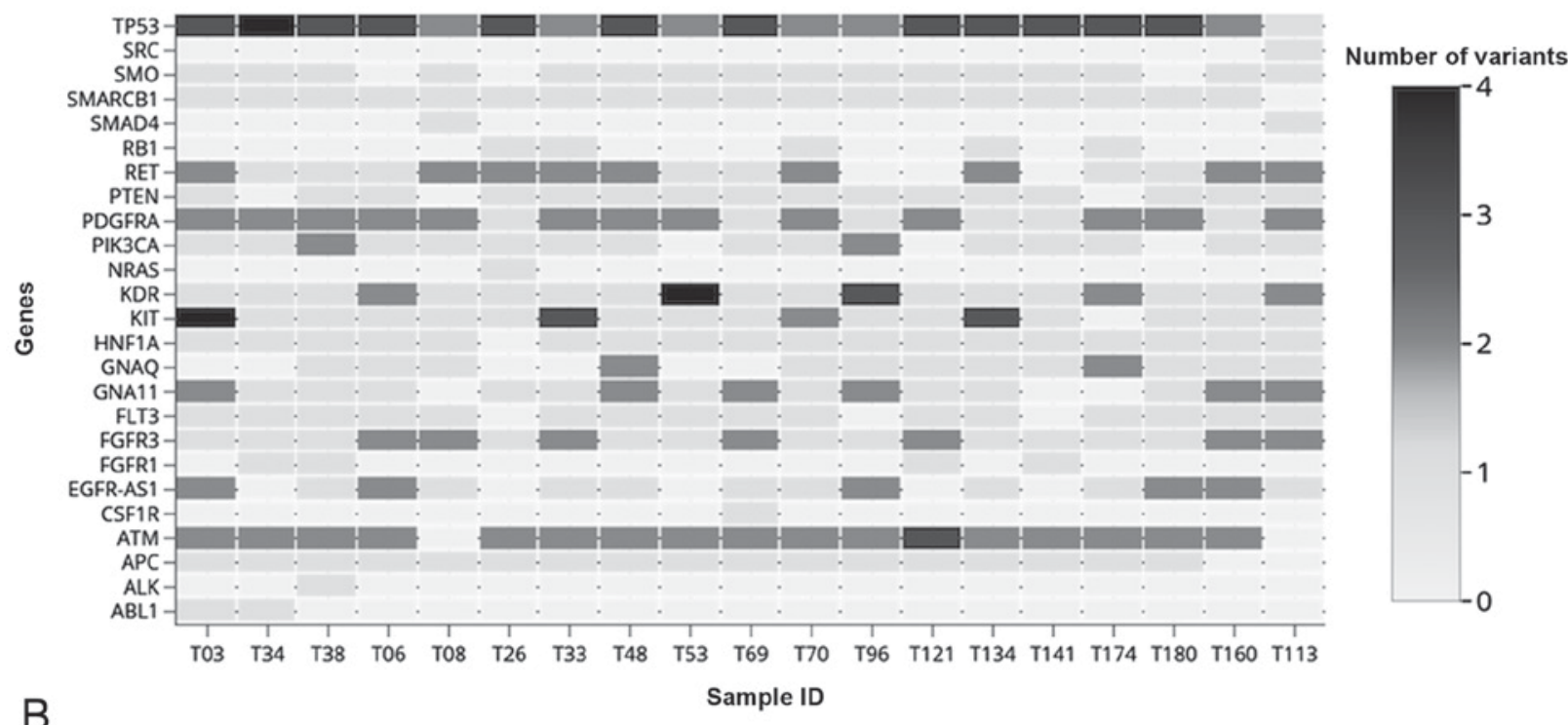

B
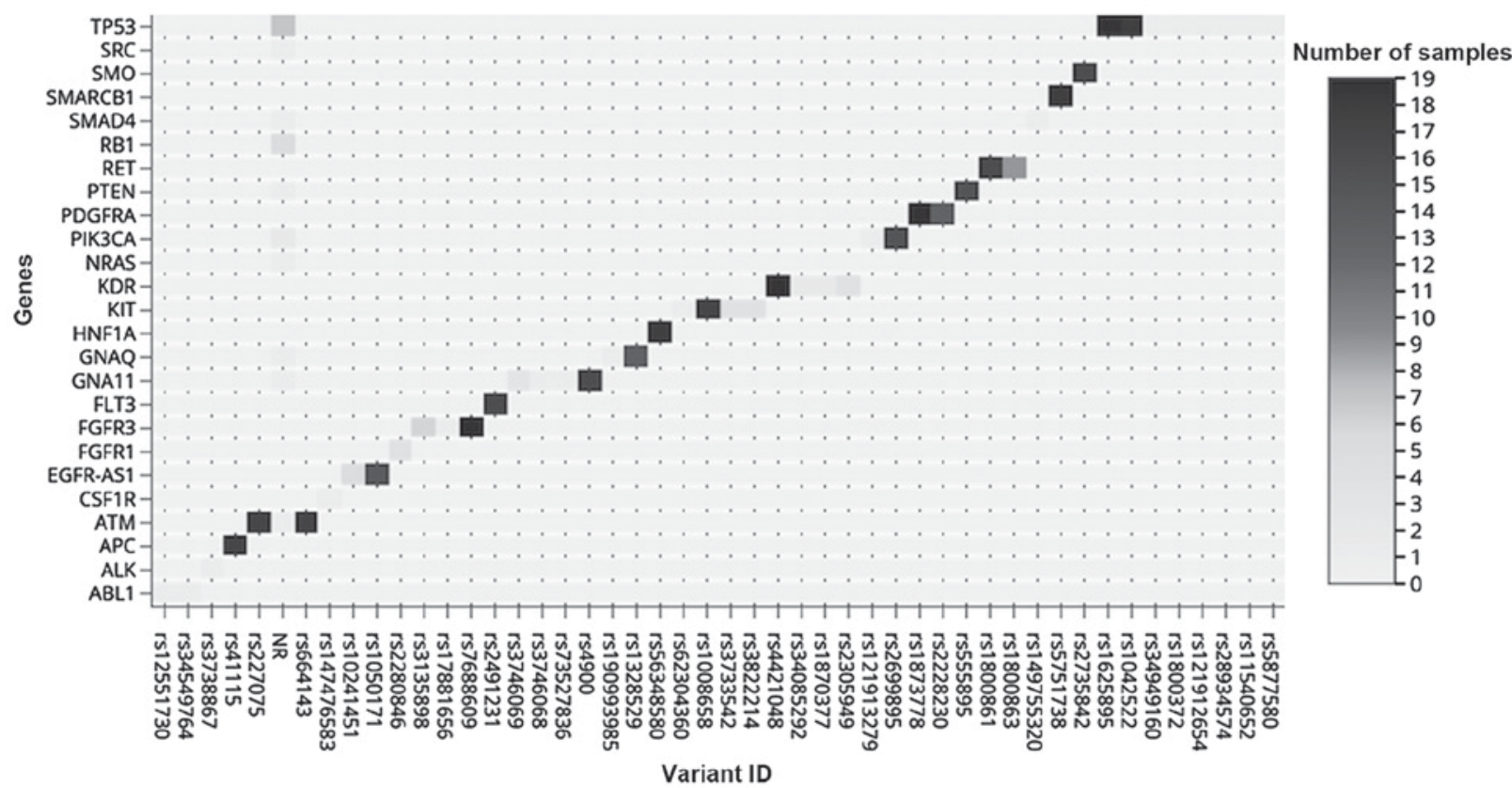

Figure 1. Distribution of the genetic variants by gene and by sample. (A) The graph shows the distribution of the variants of each gene analyzed among the patients. On the $\mathrm{x}$-axis are the sample IDs. On the $\mathrm{y}$-axis is the ID of each gene. On the right side is the gray scale color intensity code that indicates the number of variants found, with light gray $=0$ variants and darker gray=4 variants. (B) The graph shows the distribution of the variants of each gene analyzed. On the $\mathrm{x}$-axis the IDs (rs) of the variants are shown, NR=Not reported. On the $\mathrm{y}$-axis is the ID of each gene. On the right side is the gray scale color intensity code that indicates the number of samples in which each variant was found, with light gray=0 samples and darker gray=19 samples.

frameshift (11), Shah and Weisman et al (10,22), independently reported missense mutations in TP53 on TNBC whereas we found that 7 of 15 variants were missense type. TP53 is a tumor suppressor gene that encodes for a multifunctional DNA binding protein that regulates the transcription of hundreds of genes related to cell cycle regulation, differentiation, and apoptosis (23-25). The rs1042522 of TP53 corresponds to an arginine (CGC) by a proline (CCC) change in codon 72 of exon 4 . The proteins p53Arg72 and p53Pro72 do not differ in their ability to bind to DNA in a sequence-specific manner, but differ in other ways (26): p53Arg72 protein induces faster apoptosis and suppresses transformation more efficiently than the variant p53Pro72 (27,28). This variant was found in 18 of the 19 analyzed samples, and it is classified in ClinVar as drug response variant. TNBC, unlike the other BC subtypes, responds better to chemotherapy (9). Our results suggest that when p53Arg72 is present, apoptosis is more efficiently activated. However, the association of this TP53 variant with the risk of various types of cancer, including $\mathrm{BC}$, remains controversial $(29,30)$. The missense TP53 variants rs121912654 and rs28934574 have been previously associated with hepatocellular carcinoma (31) and osteosarcoma (32), respectively. The rs121912654 located in exon 5 causes the substitution of valine by phenylalanine. The rs 28934574 is located in exon 8 , and 
Table II. Genes with missense, stop gained variants or splicing region variants. TP53, PIK3CA, and FLT3 were the genes that presented variants with transcriptional consequences, in addition to intronic variants. The gene with the highest number of variants was TP53 with 15 variants; PIK3CA presented 4 variants and FLT3 presented a variant.

\begin{tabular}{|c|c|c|c|c|c|c|c|}
\hline Gene (variants) & Variant & Samples & Exon & HGVSc/HGVSp & Consequence & dbSNP & ClinVar \\
\hline \multirow[t]{15}{*}{ TP53 (15) } & $\mathrm{T}>\mathrm{C}$ & 19 & - & c. $672+62 \mathrm{~A}>\mathrm{G}$ & Intron variant & rs 1625895 & Benign \\
\hline & $\mathrm{G}>\mathrm{C}$ & 18 & $004 / 11$ & p.Pro72Arg & Missense variant & rs 1042522 & Drug response \\
\hline & $\mathrm{T}>\mathrm{C}$ & 1 & - & c. $672+31 \mathrm{~A}>\mathrm{G}$ & Intron variant & rs34949160 & Benign \\
\hline & $\mathrm{T}>\mathrm{C}$ & 1 & 006/11 & c. $639 \mathrm{~A}>\mathrm{G}(\mathrm{p} .=)$ & Synonymous variant & rs 1800372 & Benign \\
\hline & $\mathrm{G}>\mathrm{C}$ & 1 & $008 / 11$ & p.Arg282Gly & Missense variant & rs28934574 & $\begin{array}{l}\text { Pathogenic/likely } \\
\text { pathogenic }\end{array}$ \\
\hline & $\mathrm{T}>\mathrm{C}$ & 1 & $007 / 11$ & p.tyr234cys & Missense variant & rs5877580 & $\mathrm{b}$ \\
\hline & $\mathrm{C}>\mathrm{A}$ & 1 & $005 / 11$ & p.Val157Phe & Missense variant & rs 121912654 & $\mathrm{~b}$ \\
\hline & $\mathrm{C}>\mathrm{T}$ & 1 & $007 / 11$ & p.Arg248Gln & Missense variant & rs 11540652 & $\mathrm{~b}$ \\
\hline & $\mathrm{A}>\mathrm{ACG}$ & 1 & $008 / 11$ & p.Cys275PhefsTer71 & $\begin{array}{l}\text { Frameshift variant, } \\
\text { feature elongation }\end{array}$ & a & $\mathrm{b}$ \\
\hline & $\mathrm{G}>\mathrm{A}$ & 1 & $006 / 11$ & p.Arg213Ter & Stop gained & a & $\mathrm{b}$ \\
\hline & $\mathrm{A}>\mathrm{C}$ & 1 & $005 / 11$ & p.His179Gln & Missense variant & a & $\mathrm{b}$ \\
\hline & $\mathrm{G}>\mathrm{A}$ & 1 & 006/11 & p.Arg196Ter & Stop gained & a & $\mathrm{b}$ \\
\hline & $\mathrm{G}>\mathrm{C}$ & 1 & $008 / 11$ & p.Ser269Arg & Missense variant & a & $\mathrm{b}$ \\
\hline & $\mathrm{GT}>\mathrm{G}$ & 1 & $008 / 11$ & p.Asn268ThrfsTer77 & $\begin{array}{l}\text { Frameshift variant, } \\
\text { feature truncation }\end{array}$ & a & $\mathrm{b}$ \\
\hline & $\mathrm{CA}>\mathrm{C}$ & 1 & $005 / 11$ & p.Gys 135AlafsTer35 & $\begin{array}{l}\text { Frameshift variant, } \\
\text { feature truncation }\end{array}$ & a & $\mathrm{b}$ \\
\hline FLT3 (1) & $\mathrm{A}>\mathrm{G}$ & 16 & - & - & $\begin{array}{l}\text { Splice region variant, } \\
\text { intron variant }\end{array}$ & rs2491231 & $\mathrm{b}$ \\
\hline \multirow[t]{4}{*}{ PIK3CA (4) } & $\mathrm{A}>\mathrm{G}$ & 1 & - & c. $1252-27 \mathrm{~A}>\mathrm{G}$ & Intron variant & a & $\mathrm{b}$ \\
\hline & $\mathrm{G}>\mathrm{C}$ & 1 & $21 / 21$ & p.Glu1012Gln & Missense variant & a & $\mathrm{b}$ \\
\hline & $\mathrm{A}>\mathrm{G}$ & 1 & $21 / 21$ & p.His1047Arg & Missense variant & rs121913279 & $\begin{array}{l}\text { Pathogenic/likely } \\
\text { pathogenic }\end{array}$ \\
\hline & $\mathrm{C}>\mathrm{A}$ & 15 & - & c. $1059+62 \mathrm{C}>\mathrm{A}$ & Intron variant & rs2699895 & $\mathrm{b}$ \\
\hline
\end{tabular}

${ }^{a}$ Variants that have not been reported; ${ }^{b}$ variants for which there is no information in ClinVar.

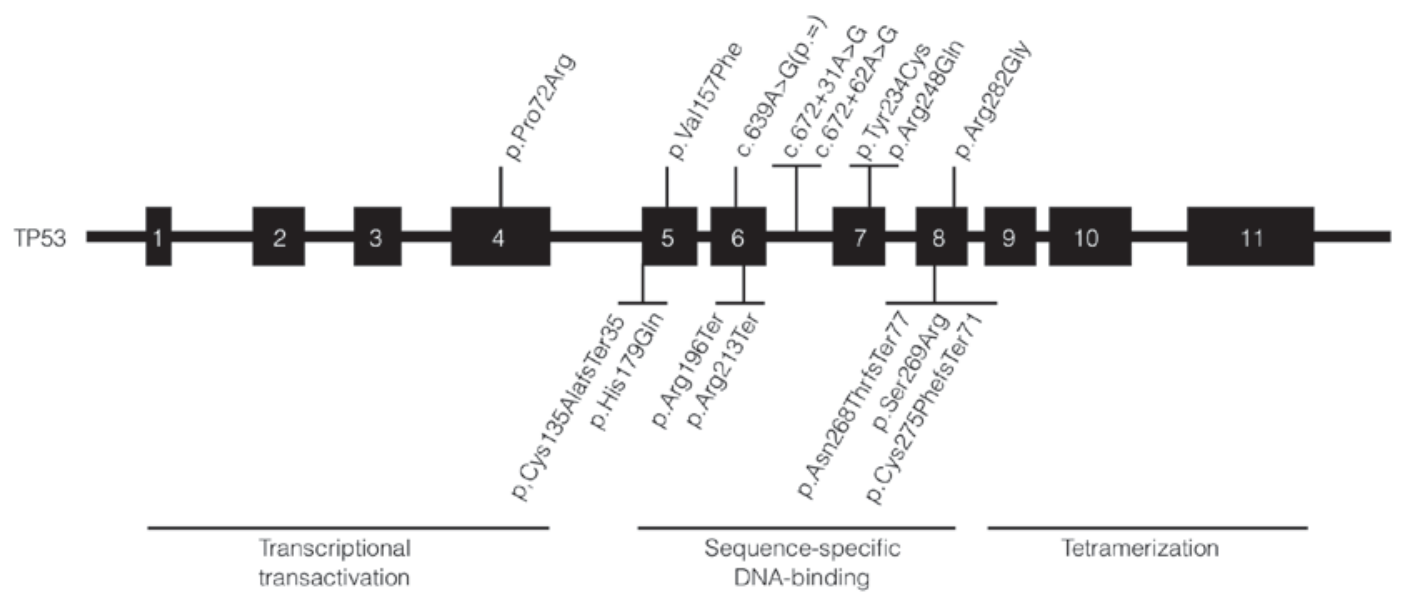

Figure 2. Map of TP53 and the domains that transcribe each region with the location of the variants reported (upwards) and not reported (downwards).

the final product is a substitution of tryptophan by arginine. The rs28934574 variant meets the criteria published in 2013 by the American College of Medical Genetics (ACMG) (33) as a variant that is recommended to inform the patient.
We found seven unreported variants in TP53 (p.Arg213Ter, p.His179Gln, p.Arg196Ter, p.Ser269Arg, p.Asn268ThrfsTer77, p.Gys135AlafsTer35 and p.Cys275PhefsTer71) in exons 5, 6, 7 and 8, which affect the 
DNA binding domain of the protein. These results match with those reported in 2014 by Silwal-Pandit et al (34). Their results conclude that more than $80 \%$ of mutations in $\mathrm{BC}$ are grouped in exons 5-8 (the rest was eliminated). They observed that the p.Arg213Ter variant was located in a hotspot area of basal tumors. We found this variant in 1 of 9 patients. It would be important to analyze whether these changes affect the function of $\mathrm{p} 53$.

PIK3CA codes for the catalytic subunit p110 alpha (p110 $\alpha)$ of the phosphatidylinositol 3-kinase enzyme (PI3K) (35). The PI3K signaling pathway is essential for several cellular processes, including cell growth, proliferation, migration, and survival (36). Some works have shown gene amplifications, deletions and, more recently, missense mutations in the PIK3CA gene in human cancers, including colon, liver, stomach, brain, lung and breast cancers (37). We found four variants of the PIK3CA gene, two of them already identified as rs2699895 and rs121913279. The first is a variant located in the intron 5. The second is a missense variant. The ancestral allele is an adenine changed by guanine, which represents a change of histidine by arginine in position 1047 of the protein. In ClinVar, it is classified as probably pathogenic since it has been associated with breast and colorectal cancer, melanoma and non-small cell lung cancer. We also found two not previously reported variants, c.1252-27A > G, and p.Glu1012Gln. The first one is located in an intronic region and the second one is located in exon 21, therefore a change from glutamic acid to glutamine is observed. In previous works, it has been reported that PIK3CA is the second most frequently mutated gene in $\operatorname{TNBC}(10,38)$. PIK3CA presents at least one variant in 15 of the 19 samples analyzed, and two samples have an exonic gene variant. It has been reported that the frequency of mutations in $P I K 3 C A$ in $\mathrm{BC}$ is $10-30 \%$ (39), what is similar to our data. However, most of the mutations reported are located in exons 9 and 20 (39). These variants produce a gain of function and transformation capacity in the PIK3CA protein, thus it is relevant to investigate the role of the variants that we found in this work. Lips and colleagues reported that mutations in PIK3CA are associated with mutations in BRCAl (40). In this work, we do not investigate the $B R C A 1$ gene, so it would be interesting to analyze this theory in these patients.

In Mexico, Vaca-Paniagua et al (41) reported TP53 and RBI as the most frequently mutated genes in TNBC by complete exome sequencing. Differences in the results found in our work with respect to $R B I$ could be attributed to the design of the study. In the work of Vaca-Paniagua, the whole exome was sequenced in paraffin embedded tissues $(n=12)$, while we sequenced the hotspot regions of the 48 genes in frozen tissue biopsies. Although they obtained a greater coverage of the gene, we have a greater depth of reading. To properly compare both studies not only an intrapopulation analysis is needed, but also an interpopulation comparison is required. Finally, differences also could be explained by the clinical criteria of selection, geographic origin of the patient and his ancestors, analytical methods, sample size, exposure to environmental risk factors and dietary, among others factors.

In addition, we found the rs2491231 variant of FLT3, which corresponds to an SNV type change for which there is no evaluation in the ClinVar database. This variant is found in a region of splicing between exons 14 and 15 that is part of the region that codes for the cytoplasmic domain of the protein. The FLT3 gene encodes a tyrosine kinase receptor class III regulating hematopoiesis. When this receptor is activated, it phosphorylates and activates multiple cytoplasmic effector molecules in pathways involved in apoptosis, proliferation, and differentiation of hematopoietic cells in the bone marrow. The most common reported mutations are located in exons 14 or 20 and result in constitutive activation of this receptor, which are observed in acute myeloid leukemia and acute lymphoblastic leukemia $(42,43)$. It would be essential to evaluate the effect of the FLT3 variant on TNBC.

It would be interesting to determine the pathogenic significance of the genetic variants reported in this work in TNBC, because these genes are potential therapeutic targets. Currently, new compounds with different specificity and potency are being developed, targeting different components of the PI3K/AKT/mTOR pathway (44), small molecule compounds that specifically target the mutant p53 $(45,46)$ and compounds that inhibit tyrosine kinase enzymes, such as FLT3 (47). Mutations in DNA are not the only form of gene regulation; it is important to consider some other molecular events, including Copy Number Variation, chromosomal and epigenetic alterations, as well as the role that play micro RNAs (miRNAs) and non-coding RNA (ncRNA) (48).

In the present study, the diagnosis of TNBC was the only criterion for the variant analysis, other factors, such as age, ethnicity as well as the mutational signature will be considered in a future study, including damage to DNA and its repair components (49). Although for this study we do not have healthy tissue and our sample number is small, we can draw some conclusions. First, the mutation spectrum remains diverse even in a carefully selected and untreated group of patients with TNBC. All samples were from the same institution and the laboratory procedures were carefully monitored. Our results strongly suggest that each tumor has its unique molecular composition. However, it is observed that the total of the biopsies studied have at least two variants in the TP53 gene. The rs1042522 drug responsive variant is the most representative, since it was found in $94 \%$ of the samples analyzed. We also found seven previously unreported variants with probable deleterious characteristics of the p53 tumor suppressor protein. The variant rs2491231 of the FLT3 gene was identified in $84 \%$ $(16 / 19)$ of the samples, which has not been reported before for TNBC.

In conclusion, we found intron, missense, stop gained and splicing variants in TP53, PIK3CA, and FLT3 genes. Some of these variants have not been reported. Studies should be carried out to elucidate if they have a role in the development of TNBC y and their possible role as therapeutic targets. It is important to validate the presence of these variants in a large cohort that includes healthy tissue and non TNBC tissue as well as in cell culture to evaluate their impact on diagnosis, prognosis and management of such aggressive TBNC.

\section{Acknowledgements}

The authors would like to thank Mrs Patricia Villarreal of Unidad de Genomica, Centro de Investigacion y Desarrollo en Ciencias de la Salud, Universidad Autonoma de Nuevo Leon for her technical assistance. 


\section{Funding}

The present study was partially supported by the SS/IMSS/ISSSTE-CONACYT-2011-162301. GIUP and SKSF had scholarships from CONACYT (CVU nos. 369773 and 217104, respectively).

\section{Availability of data and materials}

The datasets used and/or analyzed during the present study are available from the corresponding author on reasonable request.

\section{Authors' contributions}

GIUP conducted the experiments, acquired, analyzed and interpreted the data, and drafted the manuscript. SKSF designed the study, conducted the experiments, analyzed and interpreted the data, and critically revised the manuscript. CNSD made substantial contributions to the conception of the study, and drafted and critically revised the manuscript. $\mathrm{SCH}$, GMM, JFGG and JVG as clinicians, selected the patients, performed the biopsies to obtain the tissue samples, collected the clinical information from medical records and contributed to the design of the study. PRF and ARM as geneticists selected the patients and participated in the interpretation of data. JRBW and LEOR assisted in technical support during the experimental work and made substantial contributions in the analysis and intepretation of the data. GSGM, ABQ, OBQ and RGG as pathologists, conducted the histopathological diagnosis of the patients. ROL made substantial contributions to the conception and design of study, and drafted and critically revised the manuscript.

\section{Ethics approval and consent to participate}

The protocol and informed consent was approved by the Ethics and Research Committee of the Faculty of Medicine (Universidad Autonoma de Nuevo Leon), with registration number BI11-005.

\section{Patient consent for publication}

Not applicable.

\section{Competing interests}

The authors declare that they have no competing interests.

\section{References}

1. Bray F, Ferlay J, Soerjomataram I, Siegel RL, Torre LA and Jemal A: Global cancer statistics 2018: GLOBOCAN estimates of incidence and mortality worldwide for 36 cancers in 185 countries. CA Cancer J Clin 68: 394-424, 2018.

2. Soto-Perez-de-Celis E and Chavarri-Guerra Y: National and regional breast cancer incidence and mortality trends in Mexico 2001-2011: Analysis of a population-based database. Cancer Epidemiol 41: 24-33, 2016.

3. Spitale A, Mazzola P, Soldini D, Mazzucchelli L and Bordoni A Breast cancer classification according to immunohistochemical markers: Clinicopathologic features and short-term survival analysis in a population-based study from the South of Switzerland. Ann Oncol 20: 628-635, 2009.
4. Sotiriou $\mathrm{C}$ and Pusztai L: Gene-expression signatures in breast cancer. N Engl J Med 360: 790-800, 2009.

5. Weigelt B, Baehner FL and Reis-Filho JS: The contribution of gene expression profiling to breast cancer classification, prognostication and prediction: A retrospective of the last decade. J Pathol 220: 263-280, 2010.

6. Dietze EC, Sistrunk C, Miranda-Carboni G, O'Regan R and Seewaldt VL: Triple-negative breast cancer in African-American women: Disparities versus biology. Nat Rev Cancer 15: 248-254, 2015.

7. Carey LA, Dees EC, Sawyer L, Gatti L, Moore DT, Collichio F, Ollila DW, Sartor CI, Graham ML and Perou CM: The triple negative paradox: Primary tumor chemosensitivity of breast cancer subtypes. Clin Cancer Res 13: 2329-2334, 2007.

8. Liedtke C, Mazouni C, Hess KR, André F, Tordai A, Mejia JA, Symmans WF, Gonzalez-Angulo AM, Hennessy B, Green M, et al: Response to neoadjuvant therapy and long-term survival in patients with triple-negative breast cancer. J Clin Oncol 26: 1275-1281, 2008

9. Foulkes WD, Smith IE and Reis-Filho JS: Triple-negative breast cancer. N Engl J Med 363: 1938-1948, 2010.

10. Shah SP, Roth A, Goya R, Oloumi A, Ha G, Zhao Y, Turashvili G, Ding J, Tse K, Haffari G, et al: The clonal and mutational evolution spectrum of primary triple-negative breast cancers. Nature 486: 395-399, 2012.

11. Cancer Genome Atlas Network: Comprehensive molecular portraits of human breast tumours. Nature 490: 61-70, 2012.

12. Metzker ML: Sequencing technologies-the next generation. Nat Rev Genet 11: 31-46, 2010.

13. Kan Z, Jaiswal BS, Stinson J, Janakiraman V, Bhatt D, Stern HM, Yue P, Haverty PM, Bourgon R, Zheng J, et al: Diverse somatic mutation patterns and pathway alterations in human cancers. Nature 466: 869-873, 2010.

14. Wagle N, Emery C, Berger MF, Davis MJ, Sawyer A, Pochanard P, Kehoe SM, Johannessen CM, Macconaill LE, Hahn WC, et al: Dissecting therapeutic resistance to RAF inhibition in melanoma by tumor genomic profiling. J Clin Oncol 29: 3085-3096, 2011.

15. Hrstka R, Coates PJ and Vojtesek B: Polymorphisms in p53 and the p53 pathway: Roles in cancer susceptibility and response to treatment. J Cell Mol Med 13: 440-453, 2009.

16. Mroz EA, Tward AD, Pickering CR, Myers JN, Ferris RL and Rocco JW: High intratumor genetic heterogeneity is related to worse outcome in patients with head and neck squamous cell carcinoma. Cancer 119: 3034-3042, 2013.

17. Gerlinger M,Rowan AJ,Horswell S,MathM,Larkin J,Endesfelder D, Gronroos E, Martinez P, Matthews N, Stewart A, et al: Intratumor heterogeneity and branched evolution revealed by multiregion sequencing. N Engl J Med 366: 883-892, 2012.

18. Macdonald SM, Harris EE, Arthur DW, Bailey L, Bellon JR, Carey L, Goyal S, Halyard MY, Horst KC, Moran MS and Haffty BG: ACR appropriateness criteria ${ }^{\circledR}$ locally advanced breast cancer. Breast J 17: 579-585, 2011.

19. Simen BB, Yin L, Goswami CP, Davis KO, Bajaj R, Gong JZ, Peiper SC, Johnson ES and Wang ZX: Validation of a next-generation-sequencing cancer panel for use in the clinical laboratory. Arch Pathol Lab Med 139: 508-517, 2015.

20. Oren M and Rotter V: Mutant p53 gain-of-function in cancer. Cold Spring Harb Perspect Biol 2: a001107, 2010.

21. Muller PA and Vousden KH: p53 mutations in cancer. Nat Cell Biol 15: 2-8, 2013

22. Weisman PS, Ng CK, Brogi E, Eisenberg RE, Won $\mathrm{HH}$, Piscuoglio S, De Filippo MR, Ioris R, Akram M, Norton L, et al: Genetic alterations of triple negative breast cancer by targeted next-generation sequencing and correlation with tumor morphology. Mod Pathol 29: 476-488, 2016.

23. Xu H and el-Gewely MR: P53-responsive genes and the potential for cancer diagnostics and therapeutics development. Biotechnol Annu Rev 7: 131-164, 2001.

24. Levine AJ: p53, the cellular gatekeeper for growth and division. Cell 88: 323-331, 1997.

25. Wallace-Brodeur RR and Lowe SW: Clinical implications of p53 mutations. Cell Mol Life Sci 55: 64-75, 1999

26. Jones JS, Chi X, Gu X, Lynch PM, Amos CI and Frazier ML: p53 polymorphism and age of onset of hereditary nonpolyposis colorectal cancer in a Caucasian population. Clin Cancer Res 10: 5845-5849, 2004

27. Thomas M, Kalita A, Labrecque S, Pim D, Banks L and Matlashewski G: Two polymorphic variants of wild-type p53 differ biochemically and biologically. Mol Cell Biol 19: 1092-1100, 1999. 
28. Dumont P, Leu JI, Della Pietra AC III, George DL and Murphy M: The codon 72 polymorphic variants of p53 have markedly different apoptotic potential. Nat Genet 33: 357-365, 2003.

29. Soleimani A, Rahmani Y, Farshchian N, Delpisheh A, Khassi K, Shahmohammadi A and Amirifard N: The evaluation of p53 polymorphism at codon 72 and association with breast cancer in iran: A systematic review and meta-analysis. J Cancer Prev 21: 288-293, 2016.

30. Bansal A, Das P, Kannan S, Mahantshetty U and Mulherkar R: Effect of p53 codon 72 polymorphism on the survival outcome in advanced stage cervical cancer patients in India. Indian J Med Res 144: 359-365, 2016.

31. Bressac B, Kew M, Wands J and Ozturk M: Selective G to T mutations of p53 gene in hepatocellular carcinoma from southern Africa. Nature 350: 429-431, 1991.

32. Smith-Sørensen B, Gebhardt MC, Kloen P, McIntyre J, Aguilar F, Cerutti P and Børresen AL: Screening for TP53 mutations in osteosarcomas using constant denaturant gel electrophoresis (CDGE). Hum Mutat 2: 274-285, 1993.

33. Green RC, Berg JS, Grody WW, Kalia SS, Korf BR, Martin CL, McGuire AL, Nussbaum RL, O'Daniel JM, Ormond KE, et al: CORRIGENDUM: ACMG recommendations for reporting of incidental findings in clinical exome and genome sequencing. Genet Med 19: 606, 2017.

34. Silwal-Pandit L, Vollan HK, Chin SF, Rueda OM, McKinney S, Osako T, Quigley DA, Kristensen VN, Aparicio S, Børresen-Dale AL, et al: TP53 mutation spectrum in breast cancer is subtype specific and has distinct prognostic relevance. Clin Cancer Res 20: 3569-3580, 2014.

35. Volinia S, Hiles I, Ormondroyd E, Nizetic D, Antonacci R, Rocchi M and Waterfield MD: Molecular cloning, cDNA sequence, and chromosomal localization of the human phosphatidylinositol 3-kinase p110 alpha (PIK3CA) gene. Genomics 24: 472-477, 1994

36. Katso R, Okkenhaug K, Ahmadi K, White S, Timms J and Waterfield MD: Cellular function of phosphoinositide 3-kinases: Implications for development, homeostasis, and cancer. Annu Rev Cell Dev Biol 17: 615-675, 2001.

37. Karakas B, Bachman KE and Park BH: Mutation of the PIK3CA oncogene in human cancers. Br J Cancer 94: 455-459, 2006.

38. Cancer Genome Atlas Network. Comprehensive molecular portraits of human breast tumours. Nature 490: 61-70, 2012.

39. Samuels Y, Wang Z, Bardelli A, Silliman N, Ptak J, Szabo S, Yan H, Gazdar A, Powell SM, Riggins GJ, et al: High frequency of mutations of the PIK3CA gene in human cancers. Science 304: 554, 2004.

40. Lips EH, Michaut M, Hoogstraat M, Mulder L, Besselink NJ, Koudijs MJ, Cuppen E, Voest EE, Bernards R, Nederlof PM, et al: Next generation sequencing of triple negative breast cancer to find predictors for chemotherapy response. Breast Cancer Res 17: $134,2015$.
41. Vaca-Paniagua F,Alvarez-GomezRM,Maldonado-MartinezHA, Pérez-Plasencia C, Fragoso-Ontiveros V, Lasa-Gonsebatt F, Herrera LA, Cantú D, Bargallo-Rocha E, Mohar A, et al: Revealing the molecular portrait of triple negative breast tumors in an understudied population through omics analysis of formalin-fixed and paraffin-embedded tissues. PLoS One 10: e0126762, 2015.

42. Uras IZ, Walter GJ, Scheicher R, Bellutti F, Prchal-Murphy M, Tigan AS, Valent P, Heidel FH, Kubicek S, Scholl C, et al: Palbociclib treatment of FLT3-ITD+ AML cells uncovers a kinase-dependent transcriptional regulation of FLT3 and PIM1 by CDK6. Blood 127: 2890-2902, 2016.

43. Adamia S, Bar-Natan M, Haibe-Kains B, Pilarski PM, Bach C, Pevzner S, Calimeri T, Avet-Loiseau H, Lode L, Verselis S, et al: $\mathrm{NOTCH} 2$ and FLT3 gene mis-splicings are common events in patients with acute myeloid leukemia (AML): New potential targets in AML. Blood 123: 2816-2825, 2014.

44. Costa RLB, Han HS and Gradishar WJ: Targeting the PI3K/AKT/mTOR pathway in triple-negative breast cancer: A review. Breast Cancer Res Treat 169: 397-406, 2018.

45. Parrales A and Iwakuma T: Targeting oncogenic mutant p53 for cancer therapy. Front Oncol 5: 288, 2015.

46. Synnott NC, Murray A, McGowan PM, Kiely M, Kiely PA, O'Donovan N, O'Connor DP, Gallagher WM, Crown J and Duffy MJ: Mutant p53: A novel target for the treatment of patients with triple-negative breast cancer? Int J Cancer 140: 234-246, 2017.

47. Stone RM, Mandrekar SJ, Sanford BL, Laumann K, Geyer S, Bloomfield CD, Thiede C, Prior TW, Döhner K, Marcucci G, et al: Midostaurin plus chemotherapy for acute myeloid leukemia with a FLT3 mutation. N Engl J Med 377: 454-464, 2017.

48. Bautista RR, Gómez AO, Miranda AH, Dehesa AZ, Villarreal-Garza C, Ávila-Moreno F and Arrieta O: Correction to: Long non-coding RNAs: Implications in targeted diagnoses, prognosis, and improved therapeutic strategies in human nonand triple-negative breast cancer. Clin Epigenetics 10: 106, 2018.

49. Nik-Zainal S, Van Loo P, Wedge DC, Alexandrov LB, Greenman CD, Lau KW, Raine K, Jones D, Marshall J, Ramakrishna M, et al: The life history of 21 breast cancers. Cell 149: 994-1007, 2012. 